\title{
A Systematic Review of the Prevalence and Risk Factors of Depression among Iranian Adolescents
}

\author{
Homeira Sajjadi ${ }^{1}$, Seyed Hossein Mohaqeqi Kamal ${ }^{2}$, Hassan Rafiey ${ }^{2}$, Meroe Vameghi ${ }^{1}$, \\ Ameneh Setareh Forouzan ${ }^{1} \&$ Masoomeh Rezaei ${ }^{3}$ \\ ${ }^{1}$ Social Determinant of Health Research Center, University of Social Welfare and Rehabilitation Sciences, \\ Tehran, Iran \\ ${ }^{2}$ Department of Social Welfare Management, University of Social Welfare and Rehabilitation Sciences, Tehran, \\ Iran \\ ${ }^{3}$ Department of Occupational Therapy, University of Social Welfare and Rehabilitation Sciences, Tehran, Iran \\ Correspondence: Seyed Hossein Mohaqeqi Kamal, Department of Social Welfare Management, University of \\ Social Welfare and Rehabilitation Sciences, Tehran, Iran. Tel: 98-021-2218-0048. E-mail: \\ hosseinmohaqeq@gmail.com
}

Received: December 8, 2012 Accepted: December 26, 2012 Online Published: January 15, 2013

doi:10.5539/gjhs.v5n3p16 URL: http://dx.doi.org/10.5539/gjhs.v5n3p16

This study was supported by a research grant from department of social determinants of health, university of social welfare and rehabilitation, Tehran, Iran

\begin{abstract}
Depression is the most common mood and psychiatric disorder. The aim of this comprehensive study was to provide a complete picture of the prevalence and risk factors of depression. The study employed a systematic review methodology, searching Iranian and international databases. After screening and evaluating the articles, a synthesis of 53 articles was accumulated. A meta-analysis of the studies showed that the prevalence of children and adolescent depression was $43.55 \%$ using the BDI, $15.87 \%$ using SCL-90, and $13.05 \%$ using CDI. Also, the prevalence of depression was higher among girls than boys based on the BDI and CDI results. The most important factors contributing to depression were: the female sex, poor inter-parental relationship, poor adolescent-parent relationship, low socio-economic status (SES), state of parenting styles, low level of parental education, and poor academic performance. The comparatively high prevalence of depression among Iranian adolescents call for further investigation and measures.
\end{abstract}

Keywords: depression, prevalence, risk factor, adolescent, systematic review, Iran

\section{Introduction}

Depression is a common psychiatric disorder in all regions of the world (Costello, 2006). It is predicted that depressive disorders will become the first leading cause of disease burden by 2015 (WHO, 2008).Similarly, depressive disorders are also a common mental health problem among adolescents worldwide (Lopez, 2006), with the lifetime prevalence of 20-25\% (Allen et al., 2007; Murphy, 2000). Prevalence estimates vary widely across studies and countries (Lopez, 2006; Fleitlich, 2004; Pillai, 2008). In the same vein, the prevalence of depression among adolescents in Iran is variable between $14.77 \%$ (Janboozorgi, 2005) to $72 \%$ (Monirpour, 2004).

Moreover, depression among adolescents is more often missed than it is in adults (Leaf, 1996), possibly because of the prominence of irritability, mood reactivity, and fluctuating symptoms. In some cases, depression among adolescents can be viewed as an early onset and sub-form of the equivalent adult disorder owing to its strong links with recurrence later in life (Birmaher, 2004). The prevalence of depression among children is low $(<1 \%$ in most studies) (Kessler, 2001) with no gender differences, and then seems to rise substantially throughout adolescence (Green, 2005). Many factors could explain the documented post-pubertal rise in depression prevalence as adolescence is a developmental period characterized by pronounced biological and social changes (Patton, 2007; Cyranowski, 2000). 
It is important to identify the risk factors associated with depression among adolescents, as this can help control and prevent depression. Many risk factors have been reported in the literature such as the female sex (Danesh, 2007; Norozi, 2006; Genaabadi, 2010; Rahmani, 2007), poor inter-parental relationship (Ghorbani, 2003; Zahirodin, 2005; Kooroshnia, 2007), low socioeconomic status (Rostamzadeh, 2001; Shojaeezadeh, 1999; Modabernia, 2005), low level of parents' education (Mirzaand \& Jenkins, 2004; Shahnazi, 2007), and poverty (Mirza \& Jenkins, 2004). Given its vast personal, social, and economic impacts, depressive disorders create significant demands on individuals, health service providers, and the society as a whole (NICE, 2009; Thomas \& Morris, 2003). Furthermore, to assist policy development for tackling adolescent depression, empirical investigation and evidence are the prerequisites. Thus, considering the importance of depression among Iranian adolescents, a systematic review of the prevalence and risk factors of depression among adolescent in Iranian studies was conducted as no such work has been carried out to the best of our knowledge. The main question posed in the current study was as follows: (a) what is the mean prevalence of depressive disorders in adolescence in Iran; and (b) what are the associated factors?

\section{Methods}

\subsection{Search Strategy}

Quantitative studies were searched on and downloaded from Medline (pub med), SID (Scientific Information Database, www.sid.ir), Irandoc (Iranian Research Institute for information Science and Technology, Irandoc.ac.ir), Iranmedex (www.iranmedex.com), Magiran (www.magiran.com) and Iranpsych (Iranian Databases on Mental Health, Psychiatric and Psychological Research, http://iranpsych.tums.ac.ir). The electronic search was performed with no specification of language including articles from 1997 to 1 march 2011. The five keywords included, "Depression, Dysthymia, Melancholia, Mood disorder, and Iran". In this case, Boolean operators were used. References of the downloaded papers and previous reviews were critically studied through to find any relevant study missed by the electronic search. Unpublished studies/gray literature were not searched in this review.

\subsection{Inclusion/Exclusion Criteria}

A structured checklist was designed to record the adequacy of the retrieved papers from the electronic search. All papers were initially screened by reviewing the titles. In so doing, two reviewers individually evaluated each study to decide on its inclusion or exclusion in the systemic review. Reliability and validity were exactly checked in process of reviewing. In the case of any disagreement or vagueness; the three researchers discussed and reached a consensus. Where doubt remained, the paper was studied in its entirety. For inclusion, the articles had to (a) use an Iranian sample, (b) be quantitative, (c) deal with depression prevalence and risk factors, (d) include schoolchildren aged 7 to 18 , (f) be conducted over the past 15 years.

\subsection{Quality Assessment}

The research team developed two checklists for evaluating the quality of descriptive and analytical studies. After reviewing the relevant instruments, such as the Critical Appraisal Skills Program (Public Health Resource Unit, 2006), a new checklist, suitable for our purposes, was developed. The reliability of the checklist was assessed in a pilot phase before being applied to the selected studies. The methodological checklist for descriptive studies and the descriptive findings of the analytical studies assessed the following criteria: (a) sample size, (b) sampling method, and (c) reliability and validity of data collection. The checklist for analytical studies covered the following areas: (a) appropriateness of the aim of research with the study design, (b) controlling of intervening variables, (c) correct selection of samples in the study group(s), and (d) correct measurements and appropriateness of statistical analyses (e.g. the odds ratio, correlation coefficients, $p$ values and confidence interval).

\subsection{Data Extraction}

A structured checklist was used for the extraction of information on the year of publication, study design, population, sample size, prevalence, depression degree, risk factors, inclusion/exclusion criteria (including age, gender, and education), and instruments. Additional information on study results was extracted with respect to the type of instruments.

\subsection{Statistical Analysis}

A narrative synthesis of the extracted studies was formed to address the questions of the review. For the meta-analysis, after exclusion of irrelevant data, the size of the sample leading to each finding was considered and ascribed a 'weight', where-after; weight averages were calculated if the findings were sufficiently 
homogenous. In the case of significant heterogeneity, the findings were grouped into subcategories, a well-known method for approaching the heterogeneity of data (Khan et al., 2003).

\section{Results}

The electronic search yielded 4,077 results, but an initial review of titles led to the exclusion of 2,825 as they were either duplicated or published before the studied period (i.e. 1997-2011). The abstracts of the remaining 1,252 articles were reviewed to identify potentially relevant papers. Consequently, 775 were excluded mainly Due to irrelevance or because of their different study design from this review. The full texts of the remaining 477 articles were reviewed and a further 430 put aside as they had not studied adolescent groups. Thus 47 articles from which data related to adolescents were extracted and used in our review. Also, the References sections of the remaining papers and previous reviews were hand-searched and six additional studies were identified as relevant. Finally, a synthesis of 53 quantitative studies was considered qualified after the review process, an illustration of which is provided Figure 1.

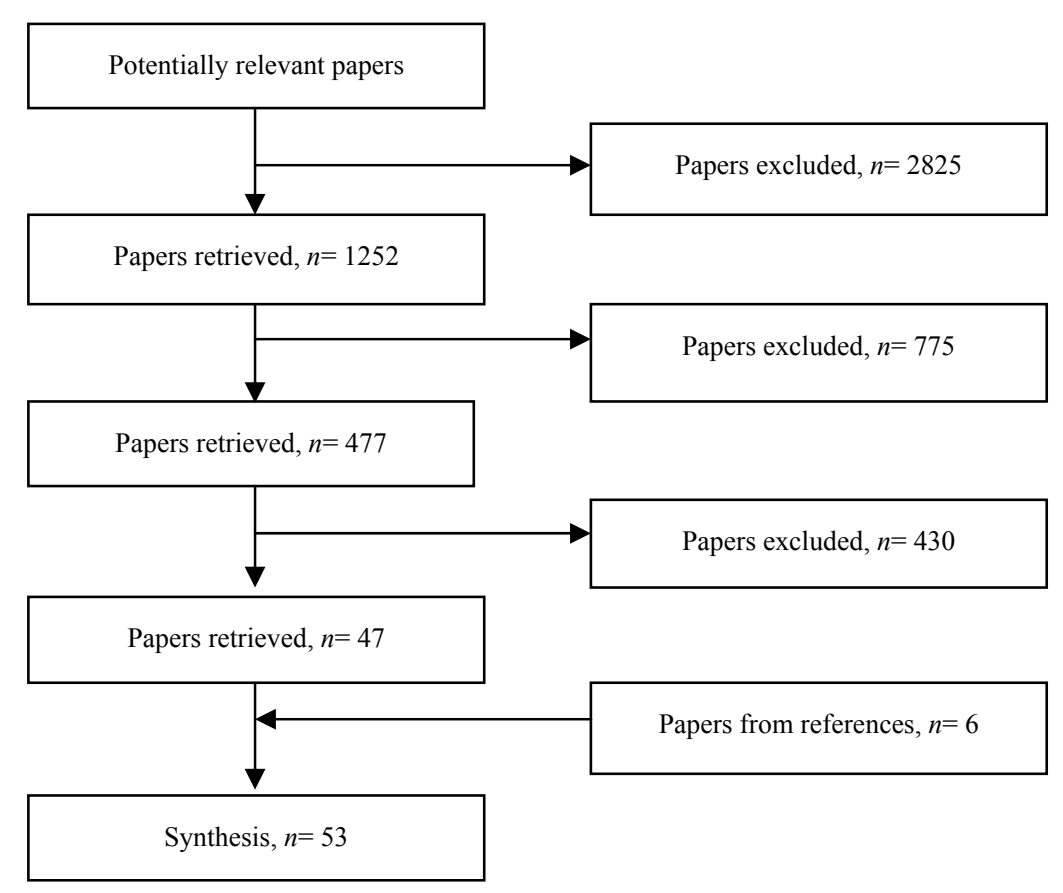

Figure 1. The process of screening article for systematic review

Results are presented under two sections namely prevalence (31 articles) and risk factors (40 articles). It should be mentioned that some papers contained data on both prevalence and risk factors, thus, included in the both categories.

\subsection{Prevalence of Depression among Adolescents}

In total, 31 studies were assigned to the prevalence of depression among Iranian adolescents. Key features of the papers are summarized in Table 1. Twelve article shad been performed using the Beck Depression Inventory (BDI) (Beck, 1961), seven articles using the Symptoms Checklist-90 (SCL-90) (Derogatis et al., 1973), five articles using the Children Depression Inventory (CDI) (Kovacs, 1981), two articles using the Zung Questionnaire (Zung, 1965), two articles using the General Health Questionnaire (GHQ) (Goldberg \& Williams, 1988), one article using the Rutter Questionnaire (Rutter, 1990), one article using the Kiddie Schedule for Affective Disorders and Schizophrenia (K-SADS) (Endicott \& Spitzer, 1978), one article using the Depression Scale for Children (CES-DC) (Kovacs, 1981), and one article a clinical interview. In one study (Janboozorgi, 2005); the BDI and CDI instruments were used together. 
Table 1. Key features of papers on prevalence

\begin{tabular}{|c|c|c|c|c|}
\hline Author & Population & Sample size & Instrument & Prevalence \\
\hline Rostamzadeh et al. (2007) 14-18 Y/O & Oromianhigh school girls & 3,023 & BDI & $68.1(\mathrm{~T})$ \\
\hline Zargham-Borojeni et al. (2002) > $=18 \mathrm{Y} / \mathrm{O}$ & Isfahani adolescents & 323 & BDI & $43.4(\mathrm{~T}), 55.5(\mathrm{G}), 30.8(\mathrm{~B})$ \\
\hline Monirpour et al. (2005) 14-18 Y/O & Sari students & 377 & BDI & $72(\mathrm{~T}), 75.3(\mathrm{G}), 65.7(\mathrm{~B})$ \\
\hline Zahirodin et al. (2005) 14-18 Y/O & Firozkohi high school students & 604 & BDI & $65.35(\mathrm{~T}), 73(\mathrm{G}), 58(\mathrm{~B})$ \\
\hline Chelsi-Roshan et al. (2003) 14-18 Y/O & Ardebilihigh school students & 967 & BDI & $26(\mathrm{~T})$ \\
\hline Rahimi-Kian et al. (2004) 14-18 Y/O & Karajihigh school students & 264 & BDI & $68.4(\mathrm{~T})$ \\
\hline Soki et al. (2007) 14-18 Y/O & Kashanihigh school girls & 762 & BDI & $53.3(\mathrm{~T})$ \\
\hline Narimani et al. (2000) 14-18 Y/O & Ardebilihigh school girls & 127 & BDI & $43(\mathrm{~T})$ \\
\hline Johari et al. (1999) 17-18 Y/O & Ilamihigh school students & 372 & BDI & $29.10(\mathrm{~T}), 31(\mathrm{G}), 27(\mathrm{~B})$ \\
\hline Mogharab et al. (2009) 14-18 Y/O & Birjandihigh school students & 450 & BDI & $58.8(\mathrm{~T})$ \\
\hline Janboozorgi et al. (2005) 12-18 Y/O & $\begin{array}{l}\text { Tehrani secondaryand high } \\
\text { school students }\end{array}$ & 1,551 & BDI & $\begin{array}{l}14.77(\mathrm{~T}), 16.14(\mathrm{G}), 13.4 \\
(B)\end{array}$ \\
\hline Modabernia et al. (2005) 14-18 Y/O & Rashtihigh school students & 4,020 & BDI & $34(\mathrm{~T})$ \\
\hline Zarabi et al. (2001) 14-18 Y/O & Rashtihigh school students & 557 & SCL-90 & $16.2(\mathrm{~T})$ \\
\hline Hosseini et al. (2002) 14-18 Y/O & Sarihigh school students & 1,536 & SCL-90 & $0.88(\mathrm{~T}), 1.04(\mathrm{G}), 0.74(\mathrm{~B})$ \\
\hline Gena-Abadi et al. (2010) 14-18 Y/O & Saravanihigh school students & 125 & SCL-90 & $26.06(\mathrm{~T}), 20.85(\mathrm{G}), 14(\mathrm{~B})$ \\
\hline Sepehrmanesh et al. (2002) 14-18 Y/O & Kashani high schoolstudents & 400 & SCL-90 & $1.04(\mathrm{~T}), 1.22(\mathrm{G}), 0.97(\mathrm{~B})$ \\
\hline Hosseinifard et al. (2000) 14-18 Y/O & Rafsanjani high schoolstudents & 830 & SCL-90 & $2.4(\mathrm{~T}), 3.1(\mathrm{G}), 1.6(\mathrm{~B})$ \\
\hline Masoodzadeh et al. (2002) 14-18 Y/O & Sarihigh school students & 1,068 & SCL-90 & $0.60(\mathrm{~T}), 0.62(\mathrm{G}), 0.58(\mathrm{~B})$ \\
\hline Hosseini et al. (1999) 14-15 Y/O & Sarisecondary school students & 350 & SCL-90 & $1.02(\mathrm{~T}), 1.41(\mathrm{G}), 0.7(\mathrm{~B})$ \\
\hline Ostovar et al. (2003) 12-18 Y/O & $\begin{array}{l}\text { Shirazi secondaryand high } \\
\text { school students }\end{array}$ & 403 & $\mathrm{CDI}$ & $\begin{array}{l}15(\mathrm{~T}), 17.07(\mathrm{G}), 11.59 \\
(\mathrm{~B})\end{array}$ \\
\hline Rajabi et al. (2001) 14-16 Y/O & $\begin{array}{l}\text { Ahvazi secondaryand high } \\
\text { school students }\end{array}$ & 400 & $\mathrm{CDI}$ & $25.6(\mathrm{~T}), 25.5(\mathrm{G}), 25.1(\mathrm{~B})$ \\
\hline Ghorbani et al. (2003) 8-16 Y/O & Isfahani adolescents & 117 & $\mathrm{CDI}$ & $8(\mathrm{~T})$ \\
\hline Abdolahian et al. (1998) 10-12 Y/O & Mashhadiadolescents & 2,071 & $\mathrm{CDI}$ & $25.6(\mathrm{~T}), 25.5(\mathrm{G}), 25.1(\mathrm{~B})$ \\
\hline Janboozorgi et al. (2005) N=18 Y/O & $\begin{array}{l}\text { Tehranielemenntary and high } \\
\text { school students }\end{array}$ & 1551 & $\mathrm{CDI}$ & $10.3(\mathrm{~T}), 13.1(\mathrm{G}), 7.6(\mathrm{~B})$ \\
\hline Motaghipour et al. (2005) 12-18 Y/O & Isfahani adolescents & 346 & GHQ & $1(\mathrm{~T}), 1.2(\mathrm{G}), 0.6(\mathrm{~B})$ \\
\hline Sadeghian et al. (2008) 14-18 Y/O & Hamadani high school girls & 600 & GHQ & $45.8(\mathrm{~T})$ \\
\hline Habibpour et al. (2001) 14-18 Y/O & Isfahanhigh school students & 400 & ZONG & $29.5(\mathrm{~T})$ \\
\hline Shojaeezadeh (1999) 14-18 Y/O & Kazeronihigh school students & 240 & ZONG & $52.9(\mathrm{~T})$ \\
\hline Shahnazi et al. (2007) $12-18 \mathrm{Y} / \mathrm{O}$ & Tabrizi adolescents & 364 & CES-DC & $75.82(\mathrm{~T})$ \\
\hline Ranjbar et al. (1998) $>=16 \mathrm{Y} / \mathrm{O}$ & Tabrizi adolescents & 252 & Rutter & $55.5(\mathrm{G}), 44.5(\mathrm{~B})$ \\
\hline Aahmad-Khaniha et al. (2001) $>=18 \mathrm{Y} / \mathrm{O}$ & Tehranistreet children & 87 & K-SADS & $61.4(\mathrm{~T}), 86.7(\mathrm{G}), 48.2(\mathrm{~B})$ \\
\hline Sayari et al. (1998) 14-18 Y/O & Tehrani high school students & 388 & $\begin{array}{l}\text { Clinical } \\
\text { interview }\end{array}$ & $72(\mathrm{~T}), 75.3(\mathrm{G}), 65.7(\mathrm{~B})$ \\
\hline
\end{tabular}

Note. $\mathrm{T}=$ total prevalence, $\mathrm{G}=$ prevalence among girls, $\mathrm{B}=$ prevalence among boys

As the current study could only the papers using the same instruments, and thereby obtain the weighted average, the mean prevalence of depression was based on three instruments including the BDI, Scl-90 and CDI. The 12 articles employing the BDI had the weighted average of $55.43 \%(N=12,851)$. The weighted average five of the seven articles using Scl-90 was $15.87 \%(N=2,262)$ (The two others-Masoodzadeh's (2002) and Hosseini's (1999) articles were excluded due to the lack of estimates of prevalence. The weighted average of the five articles using CDI was calculated to be $13.05 \%(N=4542)$. 


\subsubsection{The Prevalence of Depression by Gender}

Only the studies using the BDI and CDI as instruments furnished information on the prevalence of depression among boys and girls as two distinct groups. Thereby, the prevalence of depression by gender is presented on the basis of these two instruments. Out of the five articles measuring the prevalence of depression with [the] CDI, four articles provided the mean estimate, although Ghorbani's (2003) article was omitted due to lacking any estimate by gender. Subsequently, the weighted average of the four studies showed that the prevalence of depression was $15.32 \%$ among girls $(n=2,155)$ and $11.05 \%$ among boys $(n=2,270)$.

Eight articles which have utilized the BDI, provided prevalence mean estimate were included. The weighted average of the eight studies showed that the prevalence of depression was $57.69 \%$ among girls $(n=5,498)$ and $30.09 \%$ among boys $(n=1,652)$. Although the utilization of these instruments yielded diverse prevalence estimates of depression by gender, in both cases the mean prevalence of depression was higher for girls than boys.

\subsection{Risk Factors associated with Depression among Adolescents}

Of the 31 articles related to prevalence of depression among adolescents, 18 papers also presented information on the factors associated with adolescent depression. In addition, 22 articles specifically referred to these factors. Thus, a total of 40 articles were considered in this section, the key features of which are summarized in Table 2 .

Table 2. Risk factors associated with adolescent depression

\begin{tabular}{|c|c|c|c|c|c|c|c|c|c|c|c|c|c|}
\hline \multirow{2}{*}{ Author } & \multicolumn{13}{|c|}{ Factors associated with adolescent depression } \\
\hline & SES & PR & IA & RAP & SE & $\mathrm{P}$ & AS & ME & FE & PS & Age & $\mathrm{L}$ & $S \& D$ \\
\hline Shojaeezadeh (1999) & * & $*$ & & & & & & $*$ & & & & & \\
\hline Hosseini et al. (2002) & & & & & & & & & & & * & & \\
\hline Gena-Abadi et al. (2010) & & & & & & & & & & & & $*$ & \\
\hline Sepehrmanesh et al. (2002) & & & & & & & & & & & & & * \\
\hline Motaghipour et al. (2005) & & & & & & & & $*$ & & & & & \\
\hline \multicolumn{14}{|l|}{ Janboozorgi et al. (2005) } \\
\hline Modabernia et al. (2005) & * & & & & & & & & & & & & \\
\hline Ghorbani et al. (2003) & & * & & & & & & * & * & & & & \\
\hline Abdolahian et al. (1998) & * & & & & $*$ & & & & & & & $*$ & \\
\hline Shahnazi et al. (2007) & & & & * & $*$ & & * & $*$ & * & & & & \\
\hline Aahmad-Khaniha et al. (2001) & $*$ & & & & & & & & & & & & \\
\hline Monirpour et al. (2005) & * & & & & & & & & * & & * & & \\
\hline Zahirodin et al. (2005) & & $*$ & & $*$ & & & $*$ & & & $*$ & & & * \\
\hline \multicolumn{14}{|l|}{ Chelsi-Roshan et al. (2003) } \\
\hline Soki et al. (2007) & & & & * & & & & & $*$ & & & & \\
\hline \multicolumn{14}{|l|}{ Narimani et al. (2000) } \\
\hline \multicolumn{14}{|l|}{ Johari et al. (1999) } \\
\hline \multicolumn{14}{|l|}{ Mogharab et al. (2009) } \\
\hline \multicolumn{14}{|l|}{ Ghafari et al. (2005) } \\
\hline Kaheni et al. (2000) & & $*$ & & & & & & & & & & & \\
\hline Kooroshnia et al. (2007) & & * & & & & & & & & & & & \\
\hline Khoshnevisan et al (2011) & & & & & & & $*$ & & & & & & \\
\hline Norozi et al. (2006) & & * & & & & & & & & & & & \\
\hline Danesh et al. (2007) & & & & & & & & & & * & & & \\
\hline Sadeghzadeh et al. (2010) & & $*$ & & & & & & & & $*$ & & & \\
\hline Rahmani et al. (2007) & & & & & & & & & & * & & & \\
\hline Navabakhsh et al. (2000) & & & & & & * & & & & & & & \\
\hline Yosefi et al. (2000) & & & & & & * & & & & & & & \\
\hline Tahmasian et al. (2007) & & & & & & & * & & & & & & \\
\hline Neshatdust et al. (2005) & & * & & * & & & & * & & & & & \\
\hline Borojeni et al. (2001) & & & & * & & & & & & $\star$ & & & \\
\hline \multicolumn{14}{|l|}{ Khanjani et al. (2010) } \\
\hline Pourshirazi et al. (2007) & & & * & & & & & & & & & & \\
\hline Rostamzadeh et al. (2001) & * & * & & * & & & & * & * & & * & * & \\
\hline
\end{tabular}




\begin{tabular}{llllllllllllll}
\hline \multirow{2}{*}{ Author } & \multicolumn{1}{c}{ Factors associated with adolescent depression } \\
& SES & PR & IA & RAP & SE & P & AS & ME & FE & PS & Age & L & S\&D \\
\hline
\end{tabular}

Fakhari et al. (2001)

Seyed-Amini et al. (2009)

Rahimi-Kian et al. (2001)

Abdi et al. (2009)

Seify-Gandomani et al. (2009)

Peyvastegar et al. (2008)

\begin{tabular}{|c|c|c|c|c|c|c|c|c|c|c|c|c|c|}
\hline \multirow{2}{*}{ Author } & \multicolumn{13}{|c|}{ Factors associated with adolescent depression } \\
\hline & TS & $\mathrm{D}$ & Field & Gender & MJ & FJ & PD & $\mathrm{O} \& \mathrm{O}$ & $\mathrm{SC}$ & $\mathrm{NH}$ & HD & EA & $\mathrm{V} \& \mathrm{P}$ \\
\hline \multicolumn{14}{|l|}{ Shojaeezadeh (1999) } \\
\hline Hosseini et al. (2002) & & & & * & & & & & & & & & \\
\hline Gena-Abadi et al. (2010) & & & & * & & & & & & & & & \\
\hline Sepehrmanesh et al. (2002) & & & & * & & & & & & & & & \\
\hline Motaghipour et al. (2005) & & & & * & & & & & & & & & \\
\hline Janboozorgi et al. (2005) & * & $*$ & & * & & & & & & & & & \\
\hline Modabernia et al. (2005) & $*$ & & $*$ & * & & & & & & & & & \\
\hline Ghorbani et al. (2003) & & & & & $*$ & $*$ & * & & & & & & \\
\hline Abdolahian et al. (1998) & & & & * & & & * & & * & * & * & & \\
\hline Shahnazi et al. (2007) & & * & & & & * & & & & & & $*$ & * \\
\hline Aahmad-Khaniha et al. (2001) & & & & * & & $*$ & & & & & & & \\
\hline Monirpour et al. (2005) & & & $*$ & $*$ & & & & & & & & & \\
\hline Zahirodin et al. (2005) & & & & $*$ & & $*$ & & & & $*$ & & & $*$ \\
\hline Chelsi-Roshan et al. (2003) & * & $*$ & & & & & & & & & & & \\
\hline \multicolumn{14}{|l|}{ Soki et al. (2007) } \\
\hline Narimani et al. (2000) & $*$ & & & & & & & & & & & & \\
\hline Johari et al. (1999) & & & & * & & & & & & $*$ & & & \\
\hline Mogharab et al. (2009) & * & & & & & & & & & & & & \\
\hline Ghafari et al. (2005) & & & & & & & & & & & $*$ & & \\
\hline Kaheni et al. (2000) & & & & * & & & & & & & & & \\
\hline \multicolumn{14}{|l|}{ Kooroshnia et al. (2007) } \\
\hline \multicolumn{14}{|l|}{ Khoshnevisan et al. (2011) } \\
\hline Norozi et al. (2006) & & & & $*$ & & & & & & & & & \\
\hline Danesh et al. (2007) & & & & * & & & & & & & & & \\
\hline \multicolumn{14}{|l|}{ Sadeghzadeh et al. (2010) } \\
\hline Rahmani et al. (2007) & & & & * & & & & & & & & & \\
\hline \multicolumn{14}{|l|}{ Navabakhsh et al. (2000) } \\
\hline \multicolumn{14}{|l|}{ Yosefi et al. (2000) } \\
\hline \multicolumn{14}{|l|}{ Tahmasian et al. (2007) } \\
\hline Neshatdust et al. (2005) & & & & & & * & & & & & & & * \\
\hline \multicolumn{14}{|l|}{ Borojeni et al. (2001) } \\
\hline Khanjani et al. (2010) & & & & & & & & & & & * & & \\
\hline \multicolumn{14}{|l|}{ Pourshirazi et al. (2007) } \\
\hline Rostamzadeh et al. (2001) & & & & & * & * & & & & & & & \\
\hline \multicolumn{14}{|l|}{ Fakhari et al. (2001) } \\
\hline Seyed-Amini et al. (2009) & & & & & & & & * & & & & & \\
\hline Rahimi-Kian et al. (2001) & & * & & & & & & & & * & & & \\
\hline \multicolumn{14}{|l|}{ Abdi et al. (2009) } \\
\hline Seify-Gandomani et al. (2009) & & & & & & & & & & & * & & \\
\hline Peyvastegar et al. (2008) & & & & & & & & & & & & & \\
\hline
\end{tabular}

Note: IPR =inter-parental relationship, RAP =relationship between adolescent-parents, ME = mother's education, FE = father's education, $\mathrm{PS}=$ parenting styles, $\mathrm{AS}=$ academic success, $\mathrm{SES}=$ socioeconomic status, $\mathrm{P}=$ personality, $\mathrm{L}=$ location, $\mathrm{S} \& \mathrm{D}=$ smoking and drug abuse, $\mathrm{TS}=$ type of school, $\mathrm{D}=$ degree, $\mathrm{IA}=$ internet addiction, $\mathrm{MJ}=$ mother's job, $\mathrm{FJ}=$ father's job, $\mathrm{PD}=$ parents' divorce, $\mathrm{O} \& \mathrm{O}=$ overweight and obesity, $\mathrm{SC}=$ school change, $\mathrm{NH}=$ number of households, $\mathrm{HD}=$ history of mental illness, $\mathrm{EA}=$ extracurricular activities, $\mathrm{SE}=$ stressful events, $\mathrm{V} \& \mathrm{P}=$ violence and punishment. 
As can be inferred, more than 26 factors were associated with adolescent depression including the being female sex (15 articles), poor inter-parental relationship (nine articles), poor adolescent-parent relationship (seven articles), low socioeconomic status (six articles), low level of the mother's education (six articles), authoritarian parenting styles (six articles), low level of the father's education (five articles) and poor academic performance (five articles). All factors had a positive relationship with adolescent depression, except the last one.

Given the diversity of risk factors and lack of common data, there was no possibility for a meta-analysis. Therefore, the studies were only divided into subgroups and reported. These factors can be placed in five main subgroups:

1) Demographic factors including age, gender, parents' education, socioeconomic status, location, and number of households.

2) Communicational problems including parents' divorce, relationship between adolescent-parents, inter-parental relationship, parenting styles, violence and punishment.

3) Educational factors including poor academic performance, school change, extracurricular activities, type of school, degree, and field of education.

4) Psychological factors including a history of mental illnesses in the family, stressful events (such as death and divorce), and personality.

5) Other factors including overweight and obesity, internet addiction, smoking and drug abuse.

\section{Discussion}

In measuring depression prevalence among Iranian adolescents three instruments were used including the BDI, SCL-90 and CDI. Accordingly, the prevalence mean using the BDI was $43.55 \%$, varying between $14.77 \%$ (Janboozorgi, 2005) to $72 \%$ (Monirpour, 2005). The mean prevalence using the SCL-90 was $15.87 \%$, varying between $0.60 \%$ (Masoodzadeh, 2002) to $41.1 \%$ (Hosseini, 1999). In addition, the prevalence with CDI was $13.05 \%$, ranging between $8 \%$ (Ghorbani, 2003) to $25.6 \%$ (Rajabi, 2001).

Some of research found an increased prevalence of depression among adolescents (El-Missiry, 2012; Sarkar, 2012; Fan, 2011; Rahman, 2009). El-Missiry (2012) showed that depression in a sample of Egyptian secondary school female students was estimated to be $15.3 \%$ using the CDI (El-Missiry, 2012). Sarkar (2012) found that the prevalence of depressive disorders in school children of suburban India was 3.13\% using K-SADS-PL (Sarkar, 2012). Fan (2011) showed that the prevalence of children depression in Shanghaian children aged 8-12 years was $1.60 \%$ with K-SADS (Fan, 2011). Furthermore, the prevalence of depressive disorders among young women (16-18 years old) in rural Pakistan was 4.4\% with SCID (Rahman, 2009).

It seems evident that the prevalence of adolescent depression in Iranian studies was higher from other countries. The reason for this difference May be attributed due to diverse geographical environments, economic and cultural characteristics, and etiological and diagnostic instruments. However, population prevalence estimates may also vary widely across studies and countries due to methodological differences (from $1.6 \%$ in China (Fan, 2011) to $15.3 \%$ in Egypt (El-Missiry, 2012).

The prevalence of depression among boys and girls was based on the BDI and CDI as instruments. Accordingly, the prevalence of depression among male adolescents based on CDI was $11.05 \%$ and among female adolescents $15.32 \%$. In addition, the prevalence of depression among boys was also $30.09 \%$ and among girls $57.69 \%$ based on the BDI. Although the instruments reported different prevalence estimates, the mean prevalence of depression was higher among girls than boys.

One of the main epidemiological findings is the emergence of a strong female predisposition toward depression after puberty (Hyde, 2008). Although the reasons for this post-pubertal onset are not fully understood, adolescent depression seems more closely tied to female hormonal changes than to age (Angold, 1999). However, hormonal changes alone rarely produce the behavioral or neural signs of depression (Soares, 2008) and are more likely to contribute by sensitizing the brain to the adverse effects of stress (Hyde, 2008; Angold, 1999; Goodyer, 2000). Thus, the post pubertal gender difference in depression might in part result from increased exposure to stressors and hormonally. Finally, although depression is generally more common among girls, recognizing its extent among boys is also important. Moreover, in some subgroups (e.g., patients with Neurodevelopmental and medical disorders) this gender difference might be greatly weakened, absent, or even reversed e.g. social phobia, attention deficit hyperactivity disorder, and alcohol and drug misconduct (van Noorden, 2010). 
Results about factors associated with depression showed that more than 26 factors were associated with adolescent depression. The female sex, poor inter-parental relationship, poor adolescent-parents relationship, low socioeconomic status, low education of the mother, authoritarian parenting styles, low education of the father and poor academic performance were factors most associated with adolescent depression.

Furthermore, it seems that the gender differences cause differences in depression prevalence. Teenage girls are more prone to have mood disorders and depression such that the incidence of depression among girls compared to boys is almost two to one. These differences are probably affected by multiple factors such as biological, psychological, social, and cognitive ones (Oldehinkel, 1998).

Various researchers have found similar results as explicated here, that is, the prevalence of depression among women in Pakistan has been associated with poverty, lack of education, relationship problems, and social status of women (Mirza \& Jenkins, 2004). In addition, El-Missiry (2012) in a sample of Egyptian secondary school female students showed that depression was associated with poor academic performance, quarrelsome family atmosphere, socioeconomic status, unfavorable life events, and a family history of psychiatric disorders.

Lack of mutual understanding and agreement between parents may foster a feeling of inferiority and insecurity among children. In addition, if quarrels happen very often, anxiety and depression will probably become permanent and irritating for children. Considerable research has documented that prolonged exposure to inter parental conflict (IPC) has negative consequences for children and adolescents, including increased risk for externalizing and internalizing problems (e.g., Davies \& Windle, 2001; Emery, 1988).

Family structure and especially parent-adolescent relationship may affect adolescent depression (Puskar, 1999). To prevent depression, one of the optimal parenting styles is a democratic approach. This includes distributing affection and attention evenly among one's children, not imposing undue influence and control upon them, and leaving them free to make their own decisions. Field et al.'s (2001) study on 29 high school adolescents in the United States shows that teens with high depression degrees had a poor relationship with their parents.

Economic hardships may trigger negative parent-children interactions, leading to more intense feelings of depression, isolation, and loneliness among children (Lemperes, 1997). According to Morgan (as cited in Shahnazi, 2008), poverty and race may put children and adolescents at risk of depression.

Nrugham et al. (2008) findings found that the prevalence of depression was higher in teenagers whose parents had lower levels of education compared to those whose parents had received university or higher education. a large body of literature that highlights the importance of parental education and income for determining children's behaviors (Carlson \& Corcoran, 2001; Duncan \& Brooks-Gunn, 2000), educational performance (Magnuson, 2007), and health (Bloom, Cohen, \& Freeman, 2009).

Moreover, longitudinal investigations have demonstrated that adolescents who reported sub-syndromal levels of depressive symptoms (i.e., symptoms below the threshold of diagnosis) were at an increased risk of major depressive episodes well into adulthood, culminating in anxiety disorders, nicotine or alcohol addiction or both, educational underachievement, unemployment, early parenthood, and suicide attempts (Burns et al., 2004; Cuijpers, Graaf, \& van Dorsselaer, 2004; Fergusson, Horwood, Ridder, \& Beautrais, 2005; Lewinsohn, Solomon, Seeley, \& Zeiss, 2000).

\section{Conclusion}

It seems that there is a high prevalence of depression in adolescents. Depression in Iranian adolescents is very important, especially for girls. The most important factors contributing to depression were: the female sex, poor inter-parental relationship, poor adolescent-parent relationship, low socio-economic status (SES), state of parenting styles, low level of parental education, and poor academic performance. Also, despite the global importance of depression in adolescence and a considerable and growing body of literature, still many areas merit attention. Further development of pragmatic, cost-effective methods of detecting, measuring, and treating adolescent depression in non-specialist contexts and low-income and middle-income countries is an important priority in view of the scarcity of resources. Lack of research on preventing relapse is also noticeable. Finally, prevention strategies seem important because of the complexities and costs associated with treatment of depression among adolescents. Furthermore, enhanced coping strategies for depression among children and adolescents and review and reform of the educational system are the most important factors in prevention of depression in later life. 


\section{References}

Aahmadkhaniha, H. (2001). Epidemiology of depression and sexual abuse in street children. Iranian Journal of Psychiatry and Clinical Psychology, 8(1), 33-42. [In Persian]

Abdi, S. (2009). Relationship between identity styles, adolescent mental health, depression and academic achievement. Pajohesh nameh tarbiati, 5(21), 119-134. [In Persian]

Abdolahian, E. (1998). The prevalence of depression among school children in Mashhad. Iranian Journal of Psychiatry and Clinical Psychology, 4(28), 42-49. [In Persian]

Allen, N. B., Hetrick, S. E., Simmons, J. G., \& Hickie, I. B. (2007). Early intervention for depressive disorders in young people: the opportunity and the (lack of) evidence. Med. J. Australia, 187(7), 15-17.

Angold, A., Costello, E. J., Erkanli, A., \& Worthman, C. M. (1999). Pubertal changes in hormone levels and depression in girls. Psychol Med, 29, 1043-53. http://dx.doi.org/10.1017/S0033291799008946

Angold, A., \& Costello, E. J. (2006). Puberty and depression. Child Adolesc Psychiatr Clin N Am, 15, 919-37. http://dx.doi.org/10.1016/j.chc.2006.05.013

Rahman, A., Ahmed, M., Sikander, S., Malik, A., Tomenson, B., \& Creed, F. (2009). Young, single and not depressed: Prevalence of depressive disorder among young women in rural Pakistan. Journal of Affective Disorders, 117, 42-47. http://dx.doi.org/10.1016/j.jad.2008.12.008

Beck, A. T., Ward, C. H., Mendelson, M., Mock, J., \& Erbaugh, J. (June 1961). An inventory for measuring depression. Arch. Gen. Psychiatry, 4(6), 561-71. http://dx.doi.org/10.1001/archpsyc.1961.01710120031004

Birmaher, B., Williamson, D. E., Dahl, R. E., Axelson, D. A., Kaufman, J., Dorn, L. D., \& Ryan, N. D. (2004). Clinical presentation and course of depression in youth: does onset in childhood differ from onset in adolescence? $\mathrm{J}$ Am Acad Child Adolesc Psychiatry, 43, 63-70. http://dx.doi.org/10.1097/00004583-200401000-00015

Bloom, B., Cohen, R. A., \& Freeman, G. (2009). Summary Health Statistics for U.S. Children: National Health Interview Survey, 2008. Vital Health Statistics, 10(244), 1-81.

Borojeni, A. (2001). Parental behavior patterns associated with depression and suicidal ideation in adolescents. Journal of Shahrekord University of Medical Sciences, 3(2), 46-54. [In Persian]

Bulum, R. W., Bewhring, T., Wanderlich, M., \& Resnik, M. D. (1996). Don't ask they won't tell: the quality of adolescent health screening in five practice settings. Am $J$ Public Health, 86(12), 1767-72. http://dx.doi.org/10.2105/AJPH.86.12.1767

Carlson, M. J., \& Corcoran, M. E. (2001). Family Structure and Children's Behavioral and Cognitive Outcomes. Journal of Marriage and Family, 63, 779-792. http://dx.doi.org/10.1111/j.1741-3737.2001.00779.x

Costello, E. J., Erkanli, A., \& Angold, A. (2006). Is there an epidemic of child or adolescent depression? J Child Psychol Psychiatry, 47, 1263-71.

Cyranowski, J. M., Frank, E., Young, E., \& Shear, K. (2000). Adolescent onset of the gender difference in lifetime rates of major depression. Arch Gen Psychiatry, 57, 21-27. http://dx.doi.org/10.1001/archpsyc.57.1.21

Danesh, E. (2007). The role of parenting style and parental depression in children. Applied Psychology, 1(2), 125-141. [In Persian]

Davies, P., \& Windle, M. (2001). Inter parental discord and adolescent adjustment trajectories: The potentiating and protective role of intrapersonal attitudes. Child Development, 72, 1163-1178. http://dx.doi.org/10.1111/1467-8624.00340

Derogatis, L. R. (1983). SCL-90-R Administration, Scoring \& Procedures Manual-II. Towson, MD: Clinical Psychometric Research, 14-15.

Duncan, G. J., \& Brooks-Gunn, J. (2000). Family Poverty, Welfare Reform and Child Development. Child Development, 71, 188-196. http://dx.doi.org/10.1111/1467-8624.00133

El-Missiry, A., Soltan, M., Hadi, M. A., \& Sabry, W. (2012). Screening for depression in a sample of Egyptian secondary school female students. Journal of Affective Disorders, 136(1-2), 61-68. http://dx.doi.org/10.1016/j.jad.2011.06.031

Emery, R. E. (1982). Inter parental conflict and the children of discord and divorce. Psychological Bulletin, 92, 
310-330. http://dx.doi.org/10.1037/ 0033-2909.92.2.310

Fakhari, J. (2001). Prevalence of depression among athletes and non-athletes. Literature and Humanities, 44(180), 179-186. [In Persian]

Fan, H.-L., \& Gu, H. (2011). Prevalence of depressive disorders in shanghai children aged 8-12 years. European Psychiatry, 26(1), 623. http://dx.doi.org/10.1016/S0924-9338(11)72329-X

Field, T. (2001). Adolescent depression and risk factors. Adolescence, 36(143), 91-98.

Fleitlich-Bilyk, B., \& Goodman, R. (2004). Prevalence of child and adolescent psychiatric disorders in southeast $\begin{array}{llllll}\text { Brazil. } J \text { Am Acad Child Adolesc Psychiatry, 43, 727-34. } & \text {. }\end{array}$ http://dx.doi.org/10.1097/01.chi.0000120021.14101.ca

Genaabadi, H. (2010). Aggression, anxiety, and depression among high school adolescents. Journal of nursing and midwifery, 3(32), 148-156. [In Persian]

Ghafari, M. (2005). Severity of depressive symptoms in 14-11 children years old. Jundishapur Journal of Medicine, 4(46), 255-261. [In Persian]

Ghorbani, B. (2003). Depression in children and adolescents compared with normal families and families Divorce. Applied Psychology, 1(27), 95-112. [In Persian]

Goldberg, D., \& Williams, P. (1988). A users guide to the General Health Questionnaire. Slough: NFER-Nelson

Goodyer, I. M., Herbert, J., Tamplin, A., \& Altham, P. M. E. (2000). Recent life events, cortisol, dehydroepiandrosterone and the onset of major depression in high-risk adolescents. Br J Psychiatry, 177, 499-504. http://dx.doi.org/10.1192/bjp.177.6.499

Green, H., McGinnity, A., Meltzer, H., Ford, T., \& Goodman, R. (2005). Mental health of children and young people in Great Britain, 2004. Basingstoke, UK: Palgrave Macmillan.

Habib pour, Z. A. (2001). Comparative study of depression in adolescent. Journal of nursing and midwifery, 1(7), 8-12. [In Persian]

Hosseini, H. (2003). Assessment of mental health in students. Quarterly Journal of Fundamentals of Mental Health, 6(19), 92-99. [In Persian]

Hosseini, H. (2002). Psychopathological screening of high school students in Sari. Journal of Mazandaran University of Medical Sciences, 4(44), 22-31. [In Persian]

Hosseinifard, M. (2000). Depression and its causes. Researcher, 8(34), 106-115. [In Persian]

Hyde, J. S., Mezulis, A. H., \& Abramson, L. Y. (2008). The ABCs of depression: Integrating affective, biological, and cognitive models to explain the emergence of the gender difference in depression. Psychol Rev, 115, 291-313. http://dx.doi.org/10.1037/0033-295X.115.2.291

Janboozorgi, M. (2005). Prevalence of depression among students of Tehran. Pajohandeh, 6(48), 379-383. [In Persian]

Johari, G. (1999). Study of depression in Ilam students. Journal of Ilam University of Medical Sciences, 6(16), 34-44. [In Persian]

Kaheni, S. (2000). The study of anxiety, depression, aggression and delinquency in adolescents 19-12 years old. Journal of Sabzevar University of Medical Sciences, 7(18), 22-28. [In Persian]

Kaplan, H., \& Sadock, B. (1994). Synopsis of Psychiatry. Williamsand Wilkins Company.

Kessler, R. C., Avenevoli, S., \& RiesMerikangas, K. (2001). Mood disorders in children and adolescents: an epidemiologic perspective. Biol Psychiatry, 49, 1002-14. http://dx.doi.org/10.1016/S0006-3223(01)01129-5

Kessler, R. C. (2001). Mood disorder in children and adolescents. Biol psychiatry, 49(12), 1002-14. http://dx.doi.org/10.1016/S0006-3223(01)01129-5

Khan, S., Kunz, R., Kleignen, J., \& Antes, G. (2003). Systematic Reviews to Support Evidence Based Medicine: How to Review and Apply Findings of Healthcare Research. Royal Society of Medicine Press Ltd: London.

Khanjani, Z. (2010). Internalizing disorders of anxiety and depression in mothers' mental health in teenagers. Clinical Psychology, 2(5), 41-50. [In Persian]

Khoshnevisan, Z. (2011). The study of Relationship with Self-efficacy and depression, anxiety and stress. Journal of Kerman University of Medical Sciences, 5(20), 73-80. [In Persian] 
Kooroshnia, M. (2007). The relationship between family communication patterns of anxiety and depression in children. Family Research, 3(10), 587-600. [In Persian]

Kovacs, M. (1981). Rating scales to assess depression in school-aged children. Acta Peadopsychiatrica, 46, 305-315.

Leaf, P. J., Alegria, M., Cohen, P., Goodman, S. H., Horwitz, S. M., Hoven, C. W., ... Regier, D. A. (1996). Mental health service use in the community and schools: results from the four-community MECA Study. Methods for the epidemiology of child and adolescent mental disorders study. $J$ Am Acad Child Adolesc Psychiatry, 35, 889-97. http://dx.doi.org/10.1097/00004583-199607000-00014

Lewinsohn, P. M., Rohde, R., Klein, D. N., \& Secley, J. R. (1999). Natural course of adolescent major depressive disorder. Journal of the American Academy of child and adolescent psychiatry, 5, 91-146.

Lopez, A., Mathers, C., Ezzati, M., Jamison, D., \& Murray, C. (2006). Global burden of disease and risk factors. Washington: Oxford University Press and the World Bank. http://dx.doi.org/10.1596/978-0-8213-6262-4

Magnuson, K. (2007). Maternal Education and Children's Academic Achievement during Middle Childhood. Developmental Psychology, 43, 1497-1512. http://dx.doi.org/10.1037/0012-1649.43.6.1497

Mirza, I., \& Jenkins, R. (2004). Risk factors, prevalence, and treatment of anxiety and depressive disorders in Pakistan: systematic review. BMJ, 328(7443), 794. http://dx.doi.org/10.1136/bmj.328.7443.794

Modabernia, M. (2005). Prevalence of depression in Rasht adolescents. Journal of Gilan University of Medical Sciences, 18(71), 15-24. [In Persian]

Mogharab, M. (2011). Depression level in girls' high school students in Birjand. Scientific Quarterly of Birjand Nursing and Midwifery, 18(47), 109-116. [In Persian]

Monirpour, N. (2005). Demographic characteristics associated with depression among students. Social welfare Quarterly, 4(14), 178-183. [In Persian]

Motaghipour, Y. (2005). Mental health status among adolescents. Medical Research, 2(29), 80-85. [In Persian]

Murphy, J. M. (2000). Studying the incidence of depression: an interval effect. Int. Meth. Psychiatr. Res., 9, 184-193. http://dx.doi.org/10.1002/mpr.92

Myrna, M., Weissman, H. M., Wolk, S., Goldstein, R. B., Moreau, D., Adams, P., ... Wickramaratne, P. (1999). Depressed adolescents grown up. Journal of the American Medical Association, 281, 1707-713. http://dx.doi.org/10.1001/jama.281.18.1707

Narimani, M. (1998). Prevalence of Depression and Effectiveness of behavioral - cognitive therapy on decline in depressed students. Journal of Psychology, 6(23), 244-253. [In Persian]

Narugham, L., Larsson, B., \& Sund, A. M. (2008). Specific depressive symptomps and predictors of suicidal acts across adolescence. J Affect Disord, 111(1), 83-93. http://dx.doi.org/10.1016/j.jad.2008.02.010

Navabakhsh, M. (2000). Relationship between depression and personality in adolescent boys and girls Tehran. Psychological Science, 6(24), 395-409. [In Persian]

Neshatdost, Z. (2005). Evaluation of familial factors in adolescent depression. Family Research, 1(1), 33-40. [In Persian]

Oldehinkel, A. (1999). Prevalence, 20-month incidence and outcome of unipolar depressive disorders in a community sample of adolescents. Psychological Medicine, 29(03), 655-668. http://dx.doi.org/10.1017/S0033291799008454

Pillai, A., Patel, V., Cardozo, P., Goodman, R., Weiss, H. A., \& Andrew, G. (2008). Non-traditional lifestyles and prevalence of mental disorders in adolescents in Goa, India. $\mathrm{Br} J$ Psychiatry, 192, 45-51. http://dx.doi.org/10.1192/bjp.bp.106.034223

Pour Shirazi, M. (2007). Comparison of depression, social isolation and family relationships students. Psychological Studies, 3(2), 49-64. [In Persian]

Public Health Resource Unit. (2006). The critical appraisal program: making sense of evidence. Public Health Resource Unit: England. Retrieved August 20th, 2011 from http//www.casp-uk.net/ homepage/

Rahimikian, F. (2003). Frequency of Depression during Menstrual Period and its Relation with Religious Attitudes in Karaj High School Girls. Journal of Dena, 1(2), 1-11. [In Persian]

Rajabi, G. (2001). Factor Analysis of Child and Adolescent Depression Scale. News and Research Advisory, 1(9, 
10), 11-20. [In Persian]

Ranjbar, F. (1998). Prevalence of psychiatric disorders in Tabriz children and adolescents. Medical Journal of Tabriz University of Medical Sciences, 3(2), 465-471. [In Persian]

Rostamzadeh, Z. (2001). Prevalence of depression in high school students in Uromia. Medical Journal of uromia University of Medical Sciences, 5(2), 7-12. [In Persian]

Rutter, M. (1990). Chapter 7, Isle of Wight Revisited, Twenty-five years of child psychiatric epidemiology. In Annual Progress in Child Psychiatry and Child Development. Chess, Stella and Herzig, Margaret (eds), Psychology Press.

Sadeghian, E. (2008). Mental health status of female students in Hamadan. Medical Journal of Hamadan University of Medical Sciences, 3(57), 893-897. [In Persian]

Sadeghzadeh, M. (2010). Prediction of stress, anxiety and depression in adolescence. Journal of Psychological Methods and Models, 2(5), 61-74. [In Persian]

Sarkar, S., Sinha, V. K., \& Praharaj, S. K. (2012). Depressive disorders in school children of suburban India: An epidemiological study. Social Psychiatry and Psychiatric Epidemiology, 47(5), 783-788. http://dx.doi.org/10.1007/s00127-011-0383-7

Sayari, A. (1998). Physical and psychological health status in girl students. Journal Tebva Tazkiyeh, 13(2), 103-108. [In Persian]

Scully, I. (1995). Psychiatry, $6_{\text {th }}$ ed. Baltimor Williams \&wilkins, 1067-1070.

Sepehrmanesh, Z. (2002). Kashan school adolescents' mental health. Journal of Epidemiology, 2(10), 61-65. [InPersian]

Seyedamini, B. (2009). Overweight and obesity associated with behavioral problems. Medical Journal of Tabriz University of Medical Sciences, 31(4), 41-44. [In Persian]

Shahnazi, B. (2007). Depression among female students in public schools in Tabriz. Journal of Nursing and Midwifery, 3(9), 22-30. [In Persian]

Shojaeezadeh, D. (1999). Prevalence of depression and its influencing factors in male students. Journal of Medicine and Rehabilitation, 2(7), 23-29. [In Persian]

Soares, C. N., \& Zitek, B. (2008). Reproductive hormone sensitivity and risk for depression across the female life cycle: a continuum of vulnerability? J Psychiatry Neurosci, 33, 331-43.

Soki, Z. (2010). Depression prevalence and its correlation with the psychosocial need satisfaction among Kashan high-school female students. Feyz, Journal of Kashan University of Medical Sciences, 14(3), 256-263. [In Persian]

Tahmasian, K. (2007). Depression modeling in teens. Journal of rehabilitation, 8(29), 33-38. [In Persian]

Thomas, C. M., \& Morris, S. (2003). Cost of depression among adults in England in 2000. Br. J. Psychiatry, 183, 514-519. http://dx.doi.org/10.1192/bjp.183.6.514

van Noorden, M. S., Giltay, E. J., den Hollander-Gijsman, M. E., van der Wee, N. J., van Veen, T., \& Zitman, F. G. (2010). Gender differences in clinical characteristics in a naturalistic sample of depressive outpatients: the Leiden routine outcome monitoring study. $J$ Affect Disord, 125, 116-23. http://dx.doi.org/10.1016/j.jad.2009.12.007

WHO. (2008). Projections of mortality and burden of disease, 2004-2030. Retrieved December 4, 2010, from http://www.who.int/ healthinfo /global_burden_disease/projections/en/index.html

Zahirodin, A. (2005). Depression prevalence and associated factors among high school students. Pajohandeh, 9(37), 61-64. [In Persian]

Zargham borojeni, A. (2002). Parental behavior patterns associated with depression. Journal of Shahrekord University of Medical Sciences, 3(2), 46-54. [In Persian]

Zito, J. M., Safer, D. J., DosReis, S., Gardner, J. F., Magder, L., Soeken, K., ... Riddle, M. A. (2003). Psychotropic practice patterns for youth: a 10-year perspective. Arch Pediatr Adolesc Med, 157(1), 17-25. http://dx.doi.org/10.1001/archpedi.157.1.17

Zung, W. W. (1965). A self-rating depression scale. Archives of General Psychiatry, 12, 63-70. http://dx.doi.org/10.1001/archpsyc.1965.01720310065008 